\title{
MicroRNA-155-5p promotes tumor progression and contributes paclitaxel resistance to chemotherapy via TP53INP1 in human Breast Cancer
}

Yu Li ( $\sim$ qyqx1020153528@163.com )

Bengbu Medical College https://orcid.org/0000-0001-7866-8463

Lingyu Zhang

Zhejiang University School of Medicine Second Affiliated Hospital

Zhengyuan Dong

Bengbu Medical College

Henan Xu

Bengbu Medical College

Lei Yan

Bengbu Medical College

Shuo Yang

Bengbu Medical College

Tiantian Chen

Bengbu Medical College

Sulian Chen

Bengbu Medical College

Wenrui Wang

Bengbu Medical College

Qingling Yang

Bengbu Medical College

Changjie Chen

Bengbu Medical College

Research article

Keywords: Breast cancer, miR-155-5p, TP53INP1, migration, invasion, paclitaxel-resistance

Posted Date: March 12th, 2020

DOI: https://doi.org/10.21203/rs.3.rs-16886/v1 
License: (c) (i) This work is licensed under a Creative Commons Attribution 4.0 International License. Read Full License

Version of Record: A version of this preprint was published at Pathology - Research and Practice on April 1st, 2021. See the published version at https://doi.org/10.1016/j.prp.2021.153405. 


\section{Abstract}

Background MicroRNAs (miRNAs) are a class of small, non-coding RNAs that functioned by targeting specific mRNA. Many studies have reported that, miRNAs play a vital role in cancer progression, they can exert their functions as oncogenes or cancer suppressors. As suggested in previous report, miR-155-5p is up-regulated in breast cancer.

Results Here, we found that miR-155-5p promoted cell proliferation and inhibited cell apoptosis in MCF-7. In addition, these effects were reversed when high levels of miR-155-5p were suppressed in MCF7/PR. We determined that TP53INP1 served as a direct target of miR-155-5p through bioinformatic and luciferase assay. These findings confirmed that miR-155-5p was a tumorigenic factor that acted by targeting TP53INP1 and promoted tumor progression and contributed paclitaxel resistance to chemotherapy.

Conclusions These results contribute to our understanding of the molecular mechanism underlying breast cancer progression and resistance to chemotherapy.

\section{Background}

MiRNAs are defined as a type of short non-protein-coding RNAs, which are 18-24 nucleotides in length and, control the expression of their target genes at post-transcriptional level [1,2]. The miRNA-encoding

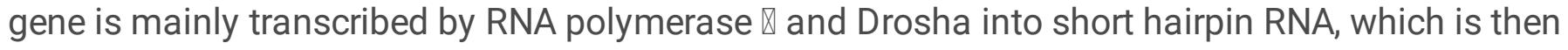
exported from the nucleus, while the mature miRNAs are processed by Dicer and eventually transferred to Argonaute proteins in RNA-induced silencing complex (RISC)[3, 4]. MiRNAs play a biological role by binding to 3' UTRs, inhibiting the expression of target genes, and resulting in specific degradation or translation inhibition of target genes, thereby down-regulating target protein expression [5]. Meanwhile, it has been found to be not only crucial for the development and maintenance of physiological homeostasis, but it also causally implicated in tissue injury and repair [6-8]. Due to the differential expression of miRNAs in tumor tissues and normal tissues, miRNAs can serve as molecular markers and monitors in neoplasm types, stage, grade, and prognosis. MiR-155 is derived from a gene called BIC located on chromosome 21 q21. It has been reported that the high level of miR-155-5p, a clinically relevant marker of several cancers, and high-level of miR-155-5p predict higher adverse survival rates and recurrence in several tissue subtypes [9-12]. Several studies have reported that the overexpression of miR-155-5p in malignant breast tumors is negatively correlated with the overall survival of breast cancer[13, 14]. Therefore, further research is needed to better characterize miR-155-5p expression and the function involved in breast cancer progression and chemotherapy resistance. In this study, we aimed to analyze miR155-5p expression profiles in breast cancer and explore the role as well as potential mechanisms of miRNA and target genes in cell migration, invasion and ineffective chemotherapy of breast cancer.

\section{Results}




\section{The expression of miR-155-5p is up-regulated in breast cancer}

To investigate the role of miR-155-5p in the pathogenesis of human breast cancer, we first determined the levels of miR-155-5p expression by in situ hybridization in another series of 57 breast cancer patients, for which clinical and prognosis data were available. This study was discussed and approved by the Ethics Committee of the First Affiliated Hospital of Bengbu Medical College, and all patients signed informed consent. We then analyzed the association between miR-155-5p and the clinic-pathological parameters of these breast cancer patients (Table 1). We found that expression of miR-155-5p was not statistically associated with age, cancer type. However, high miR-155-5p expression was associated with tumor grade, lymph node metastasis,and poor therapy response to paclitaxel. 
Table 1

The clinic-pathological characteristics of Breast Cancer patients and association with miR-155-5p expression

\begin{tabular}{|c|c|c|c|c|}
\hline Variables & Total & miR-155-5p & & P-value \\
\hline & $N=57$ & $\operatorname{Low}(\mathrm{n}=21)$ & $\operatorname{High}(n=36)$ & \\
\hline & No. & No.(\%) & No.(\%) & \\
\hline \multicolumn{5}{|l|}{ Age } \\
\hline$<50$ & 22 & $9(42.86)$ & 13(36.11) & 0.7786 \\
\hline$>50$ & 35 & $12(57.14)$ & 23(63.89) & \\
\hline \multicolumn{5}{|l|}{ Type } \\
\hline TNBC & 27 & $15(71.43)$ & $18(50)$ & 0.1655 \\
\hline Non-TNBC & 30 & $6(28.57)$ & $18(50)$ & \\
\hline \multicolumn{5}{|l|}{ TNM stage } \\
\hline 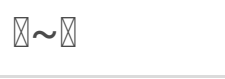 & 20 & $12(57.14)$ & $8(22.22)$ & $0.0107^{*}$ \\
\hline 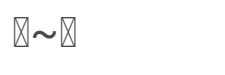 & 37 & $9(42.86)$ & $28(77.78)$ & \\
\hline \multicolumn{5}{|c|}{ Lymph node metastasis } \\
\hline Negative & 27 & 16(76.19) & $11(30.56)$ & $0.0011^{\star}$ \\
\hline Positive & 30 & $5(23.81)$ & $25(69.44)$ & \\
\hline \multicolumn{5}{|c|}{ Response to paclitaxel therapy } \\
\hline Sensitive & 25 & $14(66.67)$ & 10(27.78) & $0.0058^{*}$ \\
\hline Resistant & 32 & 7(33.33) & $26(72.22)$ & \\
\hline \multicolumn{5}{|c|}{$\begin{array}{l}\text { Paclitaxel resistance or sensitivity was defined as relapse or progression within } 6 \text { months or after } 6 \\
\text { months from the last paclitaxel-based chemotherapy, respectively. }\end{array}$} \\
\hline$* p<0.05$ & & & & \\
\hline
\end{tabular}

To verify the roles of miR-155-5p in clinical samples, we also detected endogenous expression levels of miR-155-5p in fresh normal tissues $(n=104)$ and breast cancer tissues $(n=1103)$ using TCGA database. As shown in Fig. 1A, miR-155-5p was significantly up-regulated in primary solid tumor compared with that in solid tissue normal $(P<0.0001)$. We retrieved the expression of miR-155-5p in the GEO dataset GSE45666 to verify this conclusion in Fig. 1B $(P<0.0001)$. In addition, the additional GEO dataset GSE59246 shows that in different breast tissue subtypes, miR-155-5p expression is significantly higher in invasive breast cancer (IBC) than ductal carcinoma in situ (DCIS) (Fig. 1C). To validate our findings, we confirmed miR-155-5p as an unfavorable prognostic factor in an independent cohort of Breast cancer 
samples collected from TCGA. The patients with high miR-155-5p expression were correlated with short survival time compared with those with lower miR-155-5p levels (log Rank $P=0.0047$ ) (Fig. 1D). We use receiver operating characteristic curve (ROC) to verify the efficiency of miR-155-5p as a diagnostic marker, which shows higher diagnostic efficiency in Fig. $1 E(A U C=0.7927, P<0.0001)$. Similarly, the same results were observed between MCF-7 and the corresponding MCF-7/PR as described in Fig. $1 F(P<0.001)$. Based on these results, we speculate that miR-155-5p may play an important role in promoting tumor growth and chemotherapy resistance

\section{TP53INP1 was a direct target gene of miR-155-5p}

TargetScan v7.1, miRanda, PITA, miRmap and miRTarbase were used to predict targets of miR-155-5p and 8 Top potential target genes (CEBPB, TP53INP1, MYOD, TAF5L, RNF2, KCTD3, IRF2BP2, EDEM3) were concentrated with lower $p$-value and FDR (False positive rate) by Venn diagram and detected by qRTPCR analysis after a transfection with miR-155-5p mimics and inhibitor. And TP53INP1 was identified as a potential target in MCF-7 (Fig. 2A). Next, qRT-PCR and Western blot were applied in determining the mRNA and protein expression levels of the potential target gene TP53INP1 when transfected with miR155-5p mimics, inhibitor or negative control. As shown in Fig. 2B, the expression of TP53INP1 was significantly suppressed by miR-155-5p mimics while miR-155-5p inhibitor restored TP53INP1 expression, both at mRNA and protein levels. Then we performed luciferase reporter assay to determine whether TP53INP1 was a direct target of miR-155-5p in breast cancer cells. The target region sequence of the TP53INP1 3'UTR (WT 3'UTR) or a mutant sequence containing putative miR-155-5p sites (MUT 3'UTR) was cloned into a luciferase reporter vector. As expected, the expression of miR-155-5p was strongly enhanced and the dual-luciferase activity was significantly suppressed in cells co-transfected with miR155-5p and WT-TP53INP1-3'UTR vector, but not the mutated one (Fig. 2B). To further determine whether TP53INP1 is indeed a direct target of miR-155-5p, we first examined the correlation between miR-155-5p and TP53INP1 mRNA expression in the 528 breast cancer patient dataset from TCGA Data portal. We found statistically significant inverse correlation between miR-155-5p and TP53INP1 expression in these patient samples (Pearson $r=-0.42 \mathrm{P}<0.0001$; Spearman $r=-0.308, \mathrm{P}<0.0001$ ) (Fig. $2 \mathrm{C}$ ). Therefore, to investigate the specific molecular mechanism of TP53INP1 in regulating breast cancer, expression of TP53INP1 in 1123 breast cancer tissues and 111 normal breast tissues from the TCGA Data portal was analyzed while the mRNA and protein levels of TP53INP1 were analyzed through qRT-PCR and Western blot, respectively. We found that TP53INP1 was significantly down-regulated in breast cancer tissues compared with that in normal breast tissues $(P<0.0001)$ (Fig. 2D) and that high TP53INP1 expression was correlated with long survival time relative to the low TP53INP1 levels (log rank $P<0.0001)$. Meanwhile, TP53INP1 was down-regulated in MCF-7/PR compared with MCF-7(P<0.001) (Fig. 2E).

\section{Ectopic expression miR-155-5p modulateed breast cancer cell apoptosis, migration, and invasion}


To understand the individual biological function of miR-155-5p in breast cancer, miR-155-5p mimics were transfected into MCF-7 cells whereas the miR-155-5p inhibitor was transfected into MCF-7/PR cells.

Thereafter the cell apoptosis, cell cycle, migration, and invasion were examined, qRT-PCR and Western blot were carried out to analyze the apoptosis-related genes such as Bcl-2, Caspase-3, Bak-1, Bax and target gene TP53INP1. According to Fig. 3A, miR-155-5p mimics restored the expression of the antiapoptotic gene Bcl-2 by decreasing the expression of pro-apoptotic genes Bak-1, Bax and Caspase-3 in MCF-7 cells, as suggested by the suppressed TP53INP1 expression and the decreased apoptosis rate is shown in Fig. 3C. In addition, the alteration in cell cycle distribution following miR-155-5p overexpression in the MCF-7 cells showed a restoration of cells at S phase (from 13.0 to $23.0 \%$ ), whereas the percentage of cells at the $G_{0} / G_{1}$ phase decreased (from 71.9 to $67.8 \%$ ). Further studies indicated that miR-155-5p provided potent migration and invasion activities to MCF-7 cells (Fig. 3B). Not surprisingly, these positive effects were reversed when miR-155-5p was depleted (Fig. 3D- F).

\section{TP53INP1 expression modulateed breast cancer cell growth, migration, and invasion}

The strong associations between TP53INP1 and miR-155-5p in breast cancer prompted us to investigate the effect of miR-155-5p-dependent regulation of TP53INP1 on cells apoptosis, migration and invasion abilities. As shown in Fig. S1, qRT-PCR and western blot were conducted to verify the efficiency of specific siRNA and pc-DNA3.1 constructor. Compared with negative control group, knockdown of TP53INP1 promoted cells growth, weakened the ability of migration and invasion, which was associated with an increase in Bcl-2 and a decrease in apoptotic gene levels (Fig. 4A and 4B). Cell cycle analysis showed that TP53INP1 silencing caused an increase in MCF-7 cells at S phase (from 13.0 to $18.8 \%$ ) and a reduction of cells at $\mathrm{G}_{1}$ phase (from 69.3 to $57.1 \%$ ). Furthermore, apoptosis analysis revealed a lower apoptosis rate (2.05 compared with $7.00 \%$ ) (Fig. 4C). However, over-expression of TP53INP1 positively promoted apoptosis and inhibited the migration and invasion abilities of MCF-7/PR cells, which was in contrast to the results obtained after over-expressing miR-155-5p (Fig. 4D- F).

\section{Synergistic effect of combined miR-155-5p and TP53INP1 overexpression therapy}

Since TP53INP1 has been previously shown to be a targetable marker associated with cell apoptosis, migration and invasion, MCF-7/PR cells co-contransfected with miR-155-5p inhibitor and pc-DNATP53INP1 should be an effective method in molecular therapy of cancer. In the present study, we sought to experimentally evaluate whether the dual accumulation of TP53INP1 by miR-155-5p inhibitor and pcDNA3.1 plasmid showed a synergistic effect on the biological activities of MCF-7/PR cells. As shown in Fig. 5A and 5B, the combination of miR-155-5p inhibitor and pc-DNA-TP53INP1 showed a significant TP53INP1 accumulation, more specifically, similar effects appeared in the oncogenes Bak-1, Bax and Caspase-3, while the expression of Bcl-2 was exactly the opposite, compared with the single-factor treatment groups. Since the combination of miR-155-5p inhibitor and pc-DNA-TP53INP1 showed the 
highest efficiency in TP53INP1 accumulation, such a combination was adopted to perform additional functional studies. Furthermore, we performed in vitro cell apoptosis, migration, and invasion analyses after co-transfection with miR-155-5p inhibitor and pc-DNA-TP53INP1. Similarly, in migration and invasion analyses, treatment with individual therapy significantly decreased the migratory and invasive capabilities in comparison with control treatment in MCF-7/PR. However, the combination of both treatments further enhanced the inhibition of cell migration and invasion abilities (Fig. 5C). With regard to the apoptosis and cell cycle distribution, as shown in Fig. 5C, cells apoptosis significantly increased by the co-expression of pc-DNA-TP53INP1 and miR-155-5p inhibitor, relative to the transfection of pc-DNA3.1 plasmids or inhibitor alone in MCF-7/PR cells (27.75 vs 11.85 and $11.56 \%$ ), and the fraction of cells at G0/G1 phase was significantly greater with co-transfection in transfection with single inhibitor or pc-DNA plasmids. However, the opposite results were obtained from cells at the $\mathrm{S}$ phase. The quantification of wound healing assay, migration, invasion, apoptosis and cell cycle was shown in Fig. 5D. In this study, we have introduced the concept of superimposed effects and synergistic effects. When the effect of combined treatment is significantly higher than the simple superposition of the effects of two independent factors, these effects should be considered as a synergistic effect. Further analysis found that our combination therapy has obvious synergistic effects in inhibiting cells invasion and promoting apoptosis based on Chou-Talalay combination index equation. As for cell migration and cell cycle distribution, it only showed a superimposed effect.

\section{MiR-155-5p promoted paclitaxel resistance by suppressing TP53INP1 in MCF-7/PR}

As shown in Fig. 1F and 2D, miR-155-5p was overexpressed and TP53INP1 was downregulated in MCF7/PR compared with MCF-7 cells. Therefore, we speculated that miR-155-5p and the target gene TP53INP1 may play a role in regulating the sensitivity of breast cancer cells to paclitaxel therapy. We subsequently examined the possibility that miR-155-5p treatment could contribute paclitaxel resistance through the inhibition of TP53INP1 in paclitaxel-resistant breast cancer cells. To test this possibility,MCF7/PR cells which have high intrinsic resistance to paclitaxel (IC50 $=41.25 \mu \mathrm{g} / \mathrm{ml})$ compared to MCF-7

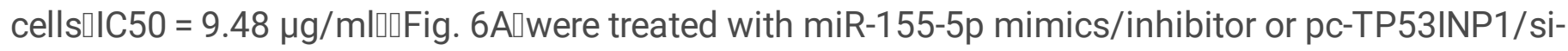
TP53INP1, and then cell apoptosis induced by paclitaxel was measured as described earlier. As shown in Fig. $6 \mathrm{~B}$ and $6 \mathrm{C}$, forced expression of miR-155-5p in paclitaxel-resistant cells significantly decreased the cytotoxicity of paclitaxel. For MCF-7/PR cells, IC50 was increased from 43.36 to $51.63 \mu \mathrm{g} / \mathrm{ml}$ (Fig. 6B), contributing to higher cells viability. Adverse results were observed in MCF-7/PR treated with miR-155-5p inhibitor (from 38.62 to $31.53 \mu \mathrm{g} / \mathrm{ml}$ as revealed in Fig. 6C). More interestingly, the IC50 of MCF-7/PR cells was reduced to a lower concentration $(22.26 \mu \mathrm{g} / \mathrm{ml})$ when transfected with pc-TP53INP1 as shown in Fig. 6D whereas opponent results revealed a decreased the cytotoxicity of paclitaxel as shown in Fig. $6 \mathrm{E}$ (from 37.18 to $45.64 \mu \mathrm{g} / \mathrm{ml}$ ). More notably, the IC50 of MCF-7/PR cells was reduced to a fairly low concentration when co-transfected with miR-155-5p inhibitor $(5.23 \mu \mathrm{g} / \mathrm{ml})$ and pc-TP53INP1, as shown in 
Fig. 6F. Therefore, our evidence indicates that miR-155-5p has important roles in cancer cell resistance to chemotherapy drugs.

\section{Discussion}

Recent studies have confirmed that miRNAs play a fatal role in the progression of several cancers, which also serve as the molecular markers for tumor diagnosis, treatment, and efficacy [15-19]. It has been many years since the earliest miRNA lin-4 and let-7 have been investigated, and this seems to be a farreaching study although the mechanism of action of miRNAs has been described due to the complex and variable genetic regulatory network. In this research, we used a large-scale cancer genome database and bioinformatics to screen and validate the dysregulation of miR-155-5p in breast cancer. Then it was confirmed that TP53INP1 was a direct target of miR-155-5p. We explored the ability of miR-155-5p in modulating cells apoptosis, migration and invasion by repressing the target gene TP53INP1 in MCF-7 and MCF-7/PR cells. In our study, we found that miR-155-5p expression was significantly up-regulated in breast cancer tissue compared with normal breast tissues. Moreover, we discovered that upregulation of miR-155-5p significantly stimulated cell growth and enhanced cell proliferation and migration, and promotes resistance of paclitaxel therapy which contributes to ineffective drug chemotherapy. However, it remains unclear about the specific mechanism by which miR-155-5p regulates the biological activity of breast cancer cells. Tumor protein 53-induced nucleoprotein 1 (TP53INP1) is a target gene of p53 that is induced by pro-apoptotic stress. It has been reported that TP53INP1 plays an important role in p53mediated apoptosis and cell cycle arrest through the p53-dependent and p53-independent pathways [20, 21]. In addition, relevant reports point out that the expression of TP53INP1 is significantly down-regulated or lost during the development of several cancers such as liver cancer, NSCLC, and pancreatic cancer[2224]. Wang et al. reported that TP53INP1, as a target gene for both miR-19a and miR-19b, TP53INP1 induced tumor cell death as a key tumor suppressor for p53, and p53 directly bound to the TP53INP1 promoter and triggered TP53INP1 in vivo accumulation[25]. In addition, it is reported that the positive rate of TP53INP1 decreases as gastric cancer progresses, and the pathological phenotype of invasive gastric carcinoma is significantly correlated with the low positive rate of TP53INP1[26, 27]. The low protein expression of TP53INP1 is significantly associated with the invasiveness of gastric cancer, and the expression of TP53INP1 gradually decreases with the progression of gastric cancer. These reports suggest that TP53INP1 may serve as a suppressor in tumor development. Our current observation together with what has been reported recently suggests that TP53INP1 is a direct target gene of miR$155[22,28-30]$. Recently results have demonstrated that estradiol (E2) promoted breast cancer development and progression possibly through increasing the expression of miR-155, which was overexpressed in MCF-7 cells, contributes to proliferation of MCF-7 cells possibly through downregulating TP53INP1[28]. It has been reported that TP53INP1 was determined to be involved in the CSCslike properties that were regulated by miR-155. Thus, miR155 may play an important role in promoting the generation of stem cell-like cells and their self-renewal by targeting the gene TP53INP1[22]. Our results showed that, the up-regulation of miR-155-5p was correlated with the down-regulation of TP53INP1. Additionally, we found that the repression of TP53INP1 by miR-155-5p was correlated with down- 
regulation of Bax, Bak-1, Caspase-3 and up-regulation of Bcl-2. These results indicated that TP53INP1 regulateed cell apoptosis through suppressing anti-apoptotic gene Bcl-2 and induceing cell apoptosis by activating pro-apoptotic genes. We also examined the synergistic effect combined with miR-155-5p inhibitor and pc-DNA-TP53INP1, which might be utilized to improve the therapeutic efficiency in cancer treatment. Finally, we verified that the high expression of microRNA-155-5p promoted breast cancer resistance to paclitaxel therapy by down-regulation of TP53INP1. It can be concluded that miR-155-5p can be used as a potential biomarker for the diagnosis of breast cancer, while monitoring tumor progression and judgment of prognosis. At the same time, our research provides new insights and directions for the molecular diagnosis and treatment of breast cancer.

The discovery of miRNAs has revolutionized research in gene expression and functional genomics. As we all know, altered metabolism of anticancer drugs is correlated with drug resistance. In clinical situations, acquired drug resistance frequently follows chemotherapeutic regimens and is considered the major cause of mortality in Breast Cancer[31-35]. Although paclitaxel has been considered the first-line chemotherapy drug for breast cancer, drug resistance leading to chemotherapy failure is almost unavoidable[36]. Increasing studies have suggested that miRNA is a new class of therapy molecule, and has a more modulatory role than traditional drugs.

\section{Conclusions}

It can be concluded that miR-155-5p can be used as a good biomarker for diagnosis and monitoring of prognosis. The combination of miR-155-5p and TP53INP1 is an effective way to strongly inhibit tumor growth and target organ metastasis. At the same time, the sensitivity of breast tumors to the chemotherapy drug paclitaxel was restored.

\section{Methods}

\section{TCGA/GEO database analysis}

TCGA (The Cancer Genome Atlas - Cancer Genome) (https://cancergenome.nih.gov/) was used to identify the differential expression of miR-155-5p in 1234 corresponding breast cancer patients (including 1103 primary solid breast tumor and 104 solid normal breast tissue) and of TP53INP1 in 1123 breast cancer tissues and 111 normal breast tissues derived from the TCGA Data portal. The patients were grouped into percentiles according to different mRNA/miRNA expression profiles. We checked for a relationship with the survival by choosing a cut-off to optimally split the samples into two groups. Optimally was defined as the significant separation in Overall survival (OS) using the optimal P values for TCGA datasets. Log-rank test was employed to determine the association between mRNA/miRNA expression and OS respectively. In addition, we also verified the expression of miR-155-5p in different breast subtype tissues in the GEO (Gene Expression Omnibus) datasets (https://www.ncbi.nlm.nih.gov/geo/) GSE45666 [37] and GSE59246 [38].

\section{Cell culture and treatments}


Breast cancer cell lines MCF-7 were purchased from The Chinese Academy of Sciences Shanghai ASTRI Cell Resource Center and cultured under the conditions specified by the manufacturer. Cells were cultured in a model of progression to paclitaxel-resistance for more than 6 months until cells exhibited resistance to cell growth inhibition by $10 \mu \mathrm{g} / \mathrm{ml}$ paclitaxel. pcDNA3.1 plasmids, siRNAs and miRNA mimics/inhibitor were transfected with OMEM (Gibco, Thermo Fisher Scientific, USA) and lip2000 reagent (Life Technologies) following the instructions of the reagent in six-well plates. The control group added equal volumes of OMEM and lip2000. TP53INP1 siRNAs or pcDNA3.1 plasmid (Gene Pharma, Shanghai, China) were used to stabilize silence or overexpression. The sequences of siRNAs for TP53INP1 were shown as follows: si-TP53INP1-1: 5'-CCU GCU UUC UCC AGU UUG ATT UCA AAC UGG AGA AAG CAG GTT-3', siTP53INP1-2: 5'-CCG UGG GAC UGA UGA AUU ATT UAA UUC AUC AGU CCC ACG GTT-3', si-TP53INP1-3: 5'GGU GGA UUA ACC ACU AUC ATT UGA UAG UGG UUA AUC CAC CTT-3'. All functional assays were performed at $24 \mathrm{~h}$ after transfection.

RNA extraction and real-time PCR. Total RNAs were extracted from cells in each group using the Trizol reagent (Invitrogen, California, USA) and analyzed by a spectrophotometer. The samples should meet the standard of: $1.8<\mathrm{OD}_{260 / 280}<2.0$. Then RNA was reversely transcribed into complementary DNA (cDNA) by using the miRNA first strand cDNA synthesis kit (Thermo Fisher Scientific, USA) for miRNA expression, as well as the reverse transcription kit (TaKaRa, Japan) for mRNA expression. Quantitative real-time PCR

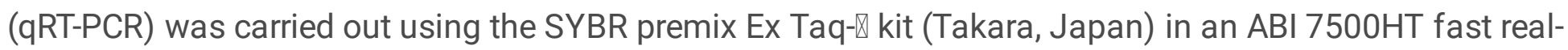
time PCR System (Applied Biosystems, USA). mRNA expression was normalized to GAPDH while miRNA level was normalized to U6 snoRNA. The following primers were used for PCR analysis: GAPDH: forward 5'-CAG CCT CAA GAT CAT CAG CA-3' reverse 5'-TGT GGT CAT GAG TCC TTC CA-3' ; TP53INP1: forward 5'GAC TTC ATA GAT ACT TGC AC-3' reverse 5'-ATT GGA CAT GAC TCA AAC TG-3' ; Bcl-2: forward 5'-ATG TGT GTG GAG AGC GTC AA-3' reverse 5'-ACA GTT CCA CAA AGG CAT CC-3' ; Bak-1: forward 5'-CCC AGG ACA CAG AGG AGG TTT-3' reverse 5'-GCC TCC TGT TCC TGC TGA TG-3' ; Bax: forward 5'-GGG GACG AAC TGG ACA GTA A-3' reverse 5'-CAG TTG AAG TTG CCG TCA GA-3' ; Caspase-3: forward 5'-ACA AAT GGA CCT GTT GAC CTG A-3' reverse 5'-ACA CCA CTG TCT GTC TCA ATG C-3'. Analysis and fold change were determined according to the the comparative threshold cycle (Ct) method.

\section{Western blot analysis}

Cells were washed by cold PBS, the whole-cell lysate was prepared with RIPA (50 mM Tris, PH 8.0), supplemented with $1 \%$ protein phosphatase inhibitors and $1 \mathrm{mM}$ PMSF (Beyotime, Shanghai, China), followed by frequent mixing and being placed on ice for $30 \mathrm{~min}$. When the lysate began to become clear, the protein was centrifuged at $4^{\circ} \mathrm{C}$ at $12000 \mathrm{rpm}$ for $15 \mathrm{~min}$. The concentration of proteins was measured by the Bio-Rad DC protein assay (Bio-Rad, USA). Where indicated, 10 or $15 \mathrm{mg}$ protein was boiled and mixed well with SDS buffer according to a certain ratio for $15 \mathrm{~min}$. Protein samples were separated and transferred onto the PVDF membranes (Bio-Rad, USA) by 10\% SDS-PAGE. Following 100 min of blocking in phosphate-buffered saline with $5 \%$ fat-free milk, membranes were incubated with the following antibodies: primary antibody: TP53INP1 (ab154877, Abcam, 1:2000); Bcl-2 (ab196495, Abcam, 1:1500); Caspase-3 (ab13586, Abcam, 1:5000); Bax (23931-1-AP, Proteintech, 1:1000); Bak-1 (24552-1-AP, 
Proteintech, 1:1000) and $\beta$-actin (sc-130065,Santa Cruz, 1:3000) together with secondary antibody: goat anti-rabbit IgG-HRP (sc-2004, Santa Cruz, 1:5000) and goat anti-mouse IgG-HRP (sc-2005,Santa Cruz, 1:5000). Bands were visualized using ChemiDoc XRS + system and Bio-Rad-Image-Lab-Software-5.2.1.

\section{MiR-155-3p target prediction}

Prediction and analysis of the target genes of miRNA were performed by TargetScan v7.1 (www.targetscan.org/), miRanda (www.microrn-a.org/), miRTarBase (mirtarbase.mbc.nctu.edu.tw/php/index.php), miRmap (https://mirmap.ezlab.org/), and PITA (genie.weizmann.ac.il/pubs/mir07/mir07data.html), respectively.

\section{Luciferase Reporter Assay}

MCF-7 cells were seeded into the 6-well plates (BD, USA) and cultured until the MCF-7 cells reached $75 \%-90 \%$ confluence. Dual-luciferase assays were performed according to instructions by using a sitedirected mutagenesis kit (Takara, Kusatsu, Japan). The activities of firefly and renilla luciferases were assayed by the dual-luciferase reporter assay system (Promega, USA) according to the reagent instructions. The luciferase activity was examined using Dual-Luciferase Reporter assay kit (Promega, USA) after transfection for $48 \mathrm{~h}$.

\section{Migration assay}

Cell migration was determined through the wound healing assay, which was also called the "scratch" assay. In brief, cells were digested with $0.25 \%$ trypsin, centrifuged, and prepared into the single cell suspension. Cell suspension was cultured into 6-well plate until the cell density reached $80 \%-90 \%$. A wound track was introduced by scraping the cell monolayer with the germ-free pipette tip $(10 \mu \mathrm{l})$. Attention should be paid to keep the same width of these cuts, then, cells were washed twice with PBS, and treated with related dose. The average extent of wound closure was quantified in 3 random fields with $\times 50$ magnification at 0 and $24 \mathrm{~h}$, respectively. All microscope images were obtained with the Olympus IX73 (Olympus Corporation, Japan).

\section{Invasion assay}

For the invasion assay, cells were digested with $0.25 \%$ trypsin, prepared into single cell suspension with serum-free medium and the cell density of each group was maintained same. According to the experimental requirements, each group of cells $\left(5 \times 10^{3}\right.$ cells per well) were seeded into the upper chamber ( $8 \mu \mathrm{m}$ pore polycarbonate membrane filters, with Matrigel (BD Biosciences, San Jose, CA, USA)), and $0.5 \mathrm{ml}$ DMEM containing 10\% FBS was added to the inferior chamber. The cells were cultured for $24 \mathrm{~h}$ at $37^{\circ} \mathrm{C}$ in $5 \% \mathrm{CO} 2$. Later, the Transwell cell culture medium was removed the membranes were fixed with $4 \%$ polyformaldehyde for 30 min, stained with Giemsa for 30 min, and counted ( 5 random fields under 200x) using light microscopy. All microscope images were obtained with Olympus IX73 (Olympus Corporation, Japan). 


\section{Apoptosis assay and Cell cycle analysis}

According to the instructions of the Muse Cell Cycle Assay Kit (Merck Millipore, USA), whole cells were washed with cold PBS, centrifugated and fixed with $70 \%$ ethyl alcohol, treated with $100 \mathrm{mg} / \mathrm{ml}$ RNase A and labeled with $50 \mathrm{mg} / \mathrm{ml}$ propidium iodide $(\mathrm{PI})$ for $1 \mathrm{~h}$ at $4{ }^{\circ} \mathrm{C}$. The experiment results were analyzed by a Muse Cell Analyzer (Merck Millipore, USA). For Annexin V staining (BD, Biosciences), whole cells were transfected and then trypsinized, washed, and resuspended in cold PBS containing with $25 \mathrm{mg} / \mathrm{ml}$ Annexin-V-FITC and $50 \mathrm{mg} / \mathrm{ml}$ 7-AAD prior to FACS analysis following the instructions of Muse Annexin V and Dead Cell kit (Merck Millipore, USA).

\section{Determination of cell viability}

The MCF-7 or MCF-7/PR cells were seeded in six-well plates at a density of $1 * 10^{5} / \mathrm{ml}$ and transfected with miR-155-5p mimics/inhibitor or pc-TP53INP1/si-TP53INP1 in three independent replicates using SRB Cell Proliferation and cytotoxicity assay kit (Boyao,Shanghai匹China) in accordance with the manufacturer's protocol. 24 hours after transfection, cells were reseeded in 96-well plates in the presence of different treatment at density of $1 \times 10^{4}$ per well and treated with paclitaxel at a range of concentration of 5 to $80 \mu \mathrm{g} / \mathrm{ml}(5,10,20,30,50,80)$ in the medium for $48 \mathrm{~h}$. The OD value was read in a microplate reader (Bio-Rad, USA) at $515 \mathrm{~nm}$. The \% cell viability was calculated with the following formula:

$\%$ Cell viability $=\left(O D_{\text {control }} / O D_{\text {treatment }}\right) \times 100$

$\%$ Cell inhibition $=1-\%$ Cell viability

In order to test the cell's resistance to paclitaxel, we tested the cell viability at different concentrations, using these data to plot XY and fit the data with a straight line (linear regression). IC50 value was then estimated using the fitted line. All these analyses and the production of pictures are done in Graphpad Prism.

\section{Statistical analysis}

All experiments were performed for at least three times, and datas were statistically analyzed using the unpaired, two-tailed Student's t-tests followed by Newman-Keuls test built into GraphPad Prism (GraphPad Software 8.0.1; San Diego, CA). All data were expressed as mean \pm SE. Furthermore, all statistical differences included a 95\% confidence interval (CI).

\section{Abbreviations}

qRT-PCR: quantitative real-time PCR; WB: Western blot; miRNA: microRNA; SDS: sodium dodecyl sulfate; NP40: Nonidet P 40; PMSF: phenylmethanesulfonyl fluoride; SDS-PAGE: polyacrylamide gelelectrophoresis; PVDF: polyvinylidene fluoride; PI: propidium iodide; PBS: phosphate Buffered Saline; DMEM: Dulbecco's modified eagle medium; IHC: immunohistochemistry; SRB: sulforhodamine B 


\section{Declarations}

Acknowledgments

Not applicable.

\section{Founding}

This study was supported by the Major Program of Anhui Educational Committee (No. KJ2019ZD28); the Key Program of college discipline (major) top-notch talent academic subsidize of Anhui (No. gxbjZD27 and 2017H110); the Key Projects of Anhui Province University Outstanding Youth Talent Support Program (No. gxyqZD2019037); the Key Program of Anhui Educational Committee (No. KJ2019A0297); the Natural Science Key Project of Bengbu Medical College (No. BYKY2019012ZD ) and the Program for graduates research of Bengbu Medical College (No. Byycx1808).

\section{Authors' contributions}

YL conceived and CJC designed the experiments. $L Y Z$ was responsible for bioinformatics analysis. YL and LYZ guaranteed the integrity of the whole research and made the clinical studies. ZYD, HNX and LY did literature research, TTC and SLC made data analysis. YL and LYZ contributed statistical analysis. WRW and QLY provided writing assistance. All authors were responsible for the editing of the manuscript. All authors read and approved the final version.

\section{Availability of data and materials}

All data generated or analyzed during this study are included in this published article.

\section{Ethics approval and consent to participate}

Not applicable.

\section{Consent for publication}

Not applicable.

\section{Competing interests}

All the authors declare that they have no conflict of interest.

\section{Author details}

${ }^{1}$ Department of Biochemistry and Molecular Biology, Bengbu Medical College, Anhui 233030, China; ${ }^{2}$ Department of Laboratory Medicine, The Second Affiliated Hospital of Zhejiang University School of Medicine, Hangzhou, Zhejiang 310009, P.R. China; ${ }^{3}$ Anhui Province Key Laboratory of Translational 
Cancer Research (Bengbu Medical College), Anhui 233030, China; ${ }^{4}$ These authors contributed equally to this work.

\section{References}

1. Yu X, Zhang X, Dhakal IB, Beggs M, Kadlubar S, Luo D. Induction of cell proliferation and survival genes by estradiol-repressed microRNAs in breast cancer cells. BMC cancer. 2012; 12 (1): 29-41. https://doi.org/10.1186/1471-2407-12-29

2. Bhat-Nakshatri P, Wang G, Collins NR, Thomson MJ, Geistlinger TR, Carroll JS, et al. Estradiolregulated microRNAs control estradiol response in breast cancer cells. Nucleic Acids Res. 2009; 37 (14): 4850-61. https://doi.org/10.1093/nar/gkp500 PMID: 19528081

3. Khvorova A, Reynolds A, Jayasena SD. Functional siRNAs and miRNAs exhibit strand bias. Cell. 2003; 115 (2): 209-16. https://doi.org/10.1016/s0092-8674(03)00801-8 PMID: 14567918

4. Schwarz DS, Hutvágner G, Du T, Xu Z, Aronin N, Zamore PD. Asymmetry in the assembly of the RNAi enzyme complex. Cell. 2003;115 (2): 199-208. https://doi.org/10.1016/s0092-8674(03)00759-1

5. Baehrecke EH. miRNAs: Micro Managers of Programmed Cell Death. Curr Bio. 2003;13 (12): R473R475. https://doi.org/10.1016/S0960-9822(03)00405-6

6. Bartel DP. MicroRNAs: Target Recognition and Regulatory Functions. Cell. 2009; 136 (2): 215-33. doi.org/10.1016/j.cell.2009.01.002

7. Hezova R, Slaby O, Faltejskova P, Mikulkova Z, Buresova I, Raja KRM, et al. microRNA-342, microRNA191 and microRNA-510 are differentially expressed in T regulatory cells of type 1 diabetic patients. Cell Immunol. 2010;260 (2): 70-4. https://doi.org/10.1016/j.cellimm.2009.10.012

8. Mendell JT, Olson EN. MicroRNAs in Stress Signaling and Human Disease. Cell. 2012; 148 (6): 117287. https://doi.org/10.1016/j.cell.2012.02.005

9. Yang M, Shen H, Qiu C, Ni Y, Wang L, Dong W, et al. High expression of miR-21 and miR-155 predicts recurrence and unfavourable survival in non-small cell lung cancer. Eur J Cancer. 2013;49 (3): 60415. https://doi.org/10.1016/j.ejca.2012.09.031

10. Marcucci G, Maharry KS, Metzeler KH, Volinia S, Wu YZ, Mrozek K, et al. Clinical role of microRNAs in cytogenetically normal acute myeloid leukemia: miR-155 upregulation independently identifies highrisk patients. J Clin Oncol. 2013; 31 (17): 2086-93. https://doi.org/10.1200/JC0.2012.45.6228 PMID: 23650424

11. Tiago DM, Conceicao N, Caiado H, Laize V, Cancela ML. Matrix Gla protein repression by miR-155 promotes oncogenic signals in breast cancer MCF-7 cells. FEBS Lett. 2016; 590 (8): 1234-41. https://doi.org/10.1002/1873-3468.12155 PMID: 27009385

12. Zhou Q, Haupt S, Kreuzer JT, Hammitzsch A, Proft F, Neumann C, et al. Decreased expression of miR146a and miR-155 contributes to an abnormal Treg phenotype in patients with rheumatoid arthritis. Ann Rheum Dis. 2015;74 (6): 1265-74. https://doi.org/10.1136/annrheumdis-2013-204377 
13. Cao W, Gao W, Liu Z, Hao W, Li X, Sun Y, Tong L, Tang B. Visualizing miR-155 To Monitor Breast Tumorigenesis and Response to Chemotherapeutic Drugs by a Self-Assembled Photoacoustic Nanoprobe. Anal Chem. 2018; 90:9125-31. https://doi.org/10.1021/acs.analchem.8b01537

14. Chen J, Wang B, Tang J. Clinical significance of MicoRNA-155 expression in human breast cancer. J Surg Oncol. 2012;106 (3): 260-6. https://doi.org/10.1002/jso.22153

15. Zhou X, Zhu W, Li H, Wen W, Cheng W, Wang F, et al. Diagnostic value of a plasma microRNA signature in gastric cancer: a microRNA expression analysis. Sci Rep. 2015; 5: 11251-8. https://doi.org/10.1038/srep11251 PMID: 26059512

16. Kurozumi A, Goto Y, Matsushita R, Fukumoto I, Kato M, Nishikawa R, et al. Tumor-suppressive microRNA-223 inhibits cancer cell migration and invasion by targeting ITGA3/ITGB1 signaling in prostate cancer. Cancer Sci. 2016; 107 (1): 84-94. https://doi.org/10.1111/cas.12842 PMID: 26509963

17. Wang S, Xiang J, Li Z, Lu S, Hu J, Gao X, et al. A plasma microRNA panel for early detection of colorectal cancer. Int J Cancer. 2015;136 (1): 152-61. https://doi.org/10.1002/ijc.28136

18. Naidu S, Magee P, Garofalo M. MiRNA-based therapeutic intervention of cancer. J Hematol Oncol. 2015;8 (1)68-75. https://doi.org/10.1186/s13045-015-0162-0

19. Jiang X, Du L, Wang L, Li J, Liu Y, Zheng G, et al. Serum microRNA expression signatures identified from genome-wide microRNA profiling serve as novel noninvasive biomarkers for diagnosis and recurrence of bladder cancer. Int J Cancer. 2015;136 (4): 854-62. https://doi.org/10.1002/ijc.29041

20. Kim EM, Jung C, Kim J, Hwang S, Park JK, Um H. The p53/p21 Complex Regulates Cancer Cell Invasion and Apoptosis by Targeting Bcl-2 Family Proteins. Cancer Res. 2017;77 (11): 3092-100. https://doi.org/10.1158/0008-5472.CAN-16-2098

21. Okamura S, Arakawa H, Tanaka T, Nakanishi H, Ng CC, Taya Y, et al. p53DINP1, a p53-Inducible Gene, Regulates p53-Dependent Apoptosis. Mol Cell. 2001; 8 (1): 85-94. https://doi.org/10.1016/S1097$\underline{2765}(\underline{01}) \underline{00284-2}$

22. Liu F, Kong X, Lv L, Gao J. MiR-155 targets TP53INP1 to regulate liver cancer stem cell acquisition and self-renewal. FEBS Letters589 (4): 500-6. https://doi.org/10.1016/j.febslet.2015.01.009

23. Li Q, Han Y, Wang C, Shan S, Wang Y, Zhang J, et al. MicroRNA-125b promotes tumor metastasis through targeting tumor protein 53-induced nuclear protein 1 in patients with non-small-cell lung cancer. Cancer Cell Int. 2015;15 (1)84-93. https://doi.org/10.1186/s12935-015-0233-x

24. Wang X, Wang L, Mo Q, Jia A, Dong Y, Wang G. A positive feedback loop of p53/miR-19/TP53INP1 modulates pancreatic cancer cell proliferation and apoptosis. Oncol Rep. 2016; 35 (1): 518-23. https://doi.org/10.3892/or.2015.4361

25. Wei Q, Li Y, Liu M, Li X, Tang H. MiR-17-5p targets TP53INP1 and regulates cell proliferation and apoptosis of cervical cancer cells. IUBMB Life. 2012;64 (8): 697-704. https://doi.org/10.1002/iub.1051

26. Wang M, Gu H, Qian H, Zhu W, Zhao C, Zhang X, et al. miR-17-5p/20a are important markers for gastric cancer and murine double minute 2 participates in their functional regulation. Eur $\mathrm{J}$ Cancer. 
2012;49 (8): 2010-21. https://doi.org/10.1016/j.ejca.2012.12.017

27. Jiang F, Liu T, He Y, Yan Q, Chen X, Wang H, et al. MiR-125b promotes proliferation and migration of type II endometrial carcinoma cells through targeting TP53INP1 tumor suppressor in vitro and in vivo. BMC cancer. 2011; 11 (1): 425-36. https://doi.org/10.1186/1471-2407-11-425

28. Zhang C, Zhao J, Deng H. 17ß-estradiol up-regulates miR-155 expression and reduces TP53INP1 expression in MCF-7 breast cancer cells. Mol cell biochem. 2013;379: 201-11.

https://doi.org/10.1007/s11010-013-1642-6

29. Liu F, Kong X, Lv L, Gao J. TGF- $\beta 1$ acts through miR-155 to down-regulate TP53INP1 in promoting epithelial-mesenchymal transition and cancer stem cell phenotypes. Cancer lett. 2013;359 (2): 28898. https://doi.org/10.1016/j.canlet.2015.01.030

30. Gironella M, Seux M, Xie M, Cano C, Tomasini R, Gommeaux J, et al. Tumor protein 53-induced nuclear protein 1 expression is repressed by miR-155, and its restoration inhibits pancreatic tumor development. P Natl Acad Sci USA. 2007;104 (41): 16170-5.

https://doi.org/10.1073/pnas.0703942104

31. Kovalchuk O, Filkowski J, Meservy J, Inytskyy Y, Tryndyak VP, Chekhun VF, et al. Involvement of microRNA-451 in resistance of the MCF-7 breast cancer cells to chemotherapeutic drug doxorubicin. Mol Cancer Ther. 2008;7 (7): 2152-2159. https://doi.org/10.1158/1535-7163.MCT-08-0021

32. Shen H, Li L, Yang S, DandanWang, Zhong S, Zhaod J, et al. MicroRNA-29a contributes to drugresistance of breast cancer cells to adriamycin through PTEN/AKT/GSK3 $\beta$ signaling pathway. Gene. 2016;593 (1): 84-90. https://doi.org/10.1016/j.gene.2016.08.016

33. Ao X, Nie P, Wu B, Xu W, Zhang T, Wang $S$, et al. Decreased expression of microRNA-17 and microRNA-20b promotes breast cancer resistance to taxol therapy by upregulation of NCOA3. Cell death dis. 2016; 7 (11): e2463-e2463. https://doi.org/10.1038/cddis.2016.367

34. Shen H, Li L, Yang S, Wang D, Zhong S. miRNA-205 targets VEGFA and FGF2 and regulates resistance to chemotherapeutics in breast cancer. Cell death dis. 2016;7 (6): e2291. https://doi.org/10.1038/cddis.2016.194

35. Yuan T, Yue W, Mohammad. F K, Wang B. Classification, Treatment Strategy, and Associated Drug Resistance in Breast Cancer. Clin breast cancer. 2016;16 (5): 335-43. https://doi.org/10.1016/j.clbc.2016.05.012

36. Péron J, Ceruse P, Lavergne E, Buiret G, Pham B, Chabaud S, et al. Paclitaxel and cetuximab combination efficiency after the failure of a platinum-based chemotherapy in recurrent/metastatic head and neck squamous cell carcinoma. Anti-cancer drugs. 2012;23 (9): 996-1001. https://doi.org/10.1097/CAD.0b013e32835507e5

37. Lee $\mathrm{C}$, Kuo W, Lin C, Oyang $\mathrm{Y}$, Huang H, Juan H. MicroRNA-Regulated Protein-Protein Interaction Networks and Their Functions in Breast Cancer. Int J Mol Sci. 2013;14 (6): 11560-606. https://doi.org/10.3390/ijms140611560

38. Lesurf R, Aure MR, Mørk HH, Vitelli V, Lundgren S, Børresen-Dale A, et al. Molecular Features of Subtype-Specific Progression from Ductal Carcinoma in Situ to Invasive Breast Cancer. Cell Rep. 


\section{Supplementary Figure}

Fig.S1 Selection of specific siRNA fragments and pcDNA3.1 plasmids for TP53INP1. a qRT-PCR and western blotting analysis were performed to measure the expression of TP53INP1 after three specific siRNAs transfection. b qRT-qPCR and western blotting analysis were performed to measure the overexpression of TP53INP1 after specific plasmid vectors. (The asterisks show difference significant as $* \star * \mathrm{P}<0.001 ; * * \mathrm{P}<0.01)$

\section{Figures}
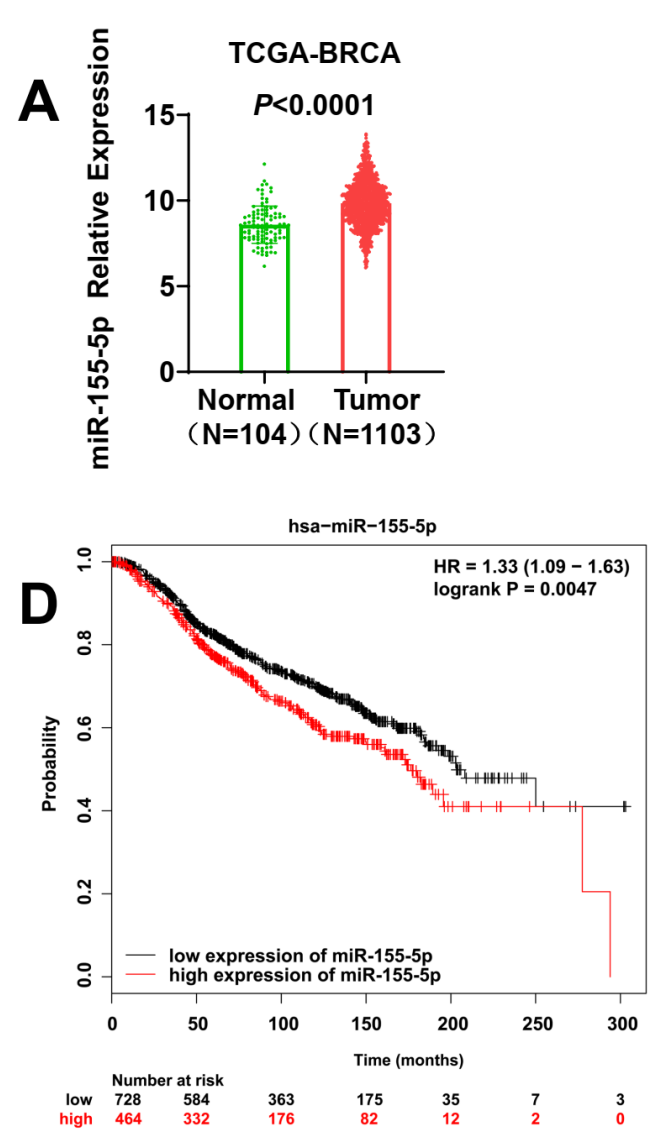
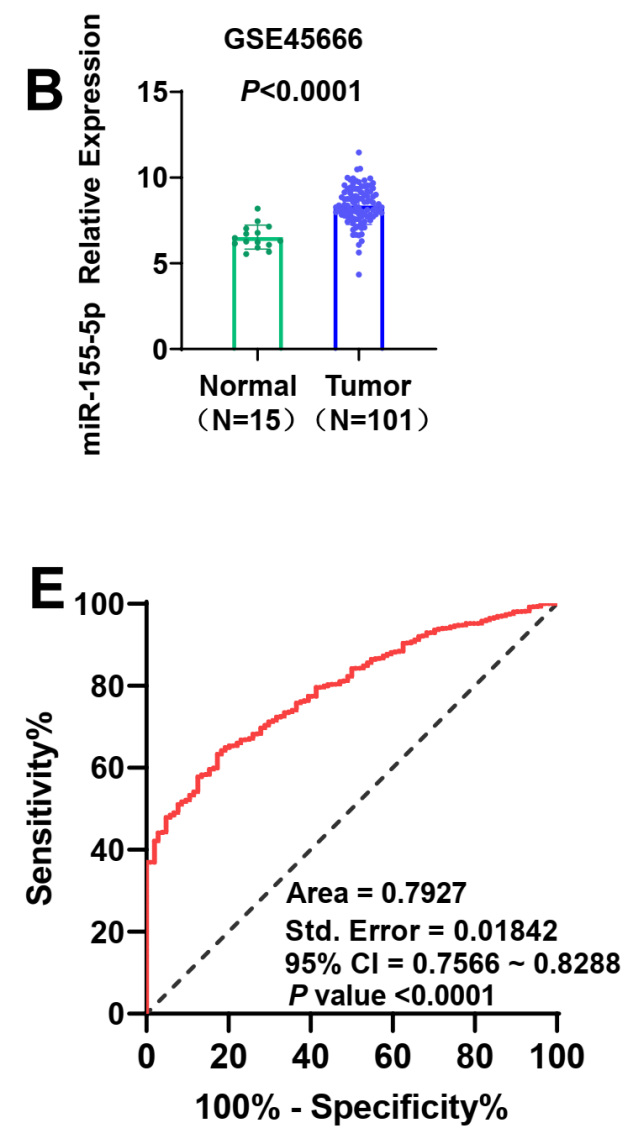
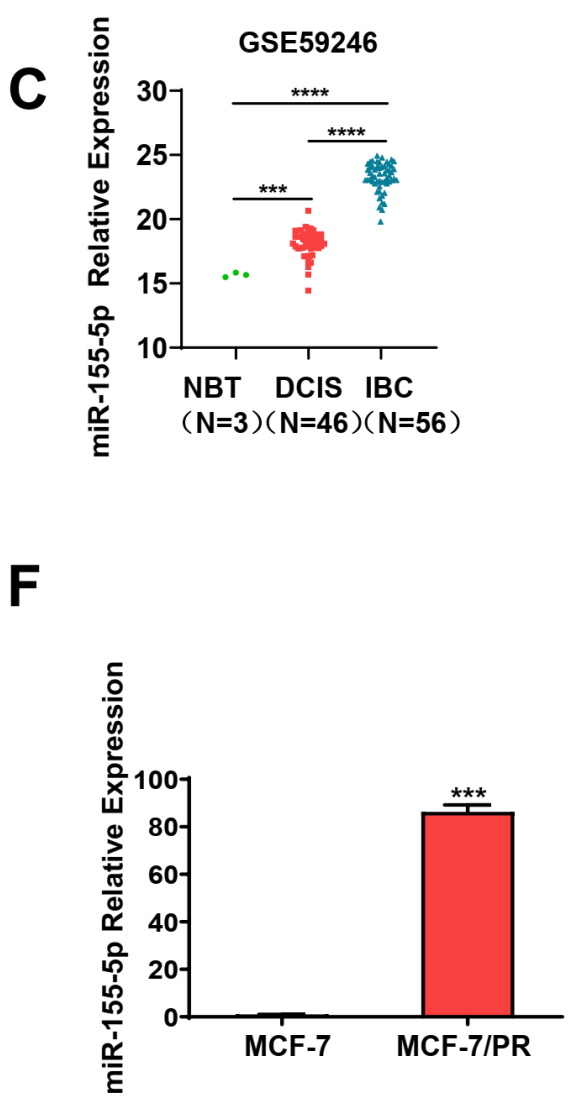

\section{Figure 1}

The expression of miR-155-5p is up-regulated and can be considered as an independent prognostic factor in human breast cancer. a miR-155-5p is over-expression in primary solid breast tumor tissues $(\mathrm{N}=1103)$ compared with solid normal tissues $(\mathrm{N}=104)$. $\mathrm{b}$ The expression of miR-155-5p in tumor tissues is higher than that in normal tissues in the GEO dataset GES45666 c miR-155-5p expression is significantly higher in invasive breast cancer (IBC) than ductal carcinoma in situ (DCIS). $d$ Kaplan-Meier curves representing the percent overall survival in patients with breast cancer based on miR-155-5p median expression levels 
in the TCGA database. e ROC curve shows miR-155-5p is a good biomarker for breast cancer diagnosis $f$ QRT-PCR analysis confirms the expression of miR-155-5p between MCF-7/PR vs MCF-7. (The asterisks show difference significant as $* \star \star * P<0.0001 ; * \star \star P<0.001)$

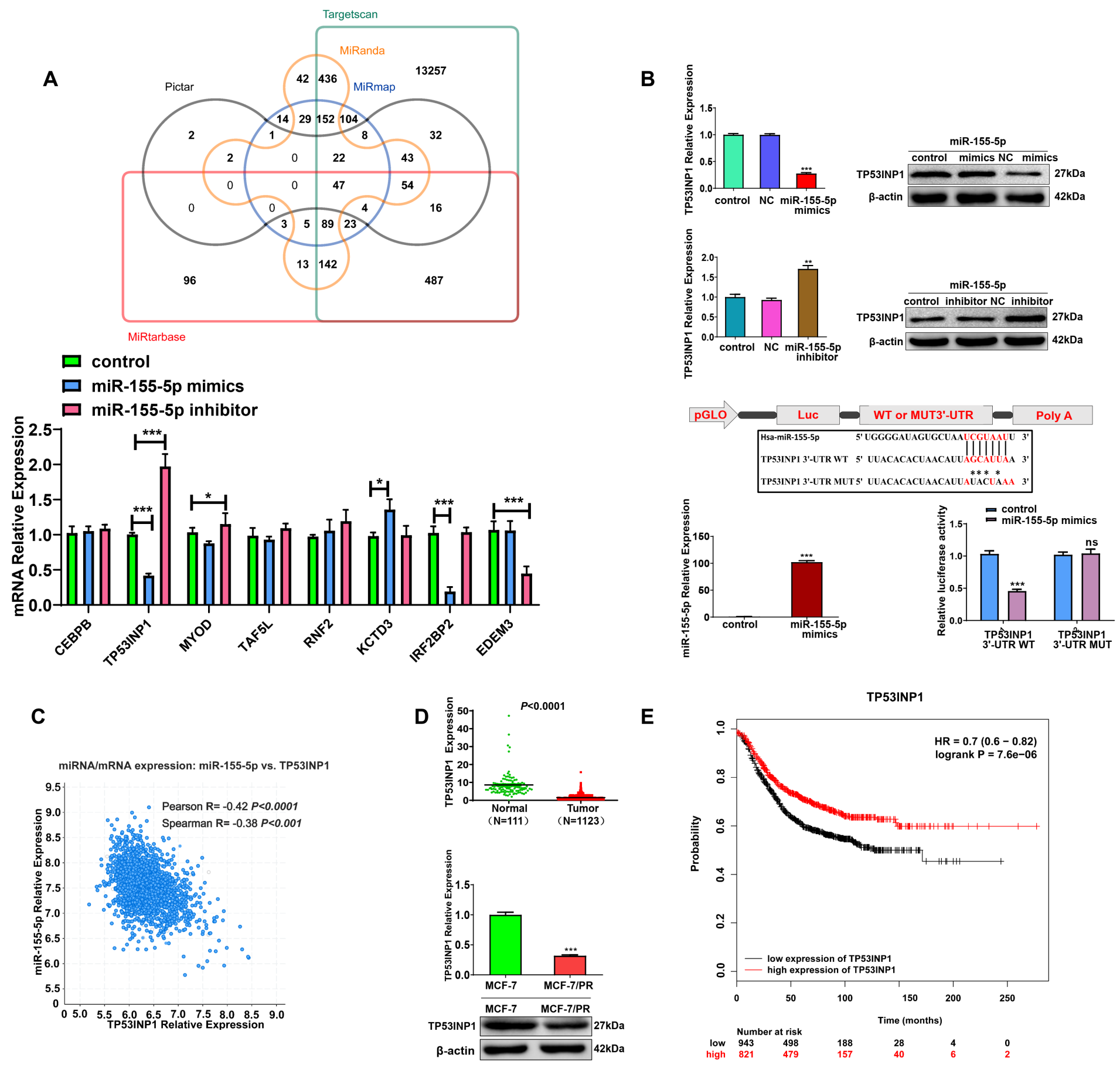

Figure 2

TP53INP1 is a direct and functional target of miR-155-5p. a 8 potential target genes (CEBPB, TP53INP1, MYOD, TAF5L, RNF2, KCTD3, IRF2BP2, EDEM3) were concentrated with lower $p$-value and FDR (False positive rate) by Venn diagram and detected by qRT-PCR analysis. $b$ Target gene validation using qRTPCR, Western Blot, and Dual-luciferase reporter assay. c Scatter plot showing negative correlation 
between TP53INP1 mRNA and miR-155-5p in TCGA patient set using Pearson's $(R=-0.42 ; P<0.001)$ and Spearman's correlation analysis $(R=-0.308 ; P<0.001)$. $d$ The potential target gene TP53INP1 expression in primary solid breast tumor tissues $(\mathrm{N}=1123)$ compared with solid normal tissues $(\mathrm{N}=111)$ and mRNA or protein levels between MCF-7 and MCF-7/PR. e Kaplan-Meier curves representing the percent overall survival in patients with breast cancer based on TP53INP1 median expression levels in the TCGA database. (The asterisks show difference significant as *** $P<0.001 ; * * P<0.01 ; * P<0.05$ )
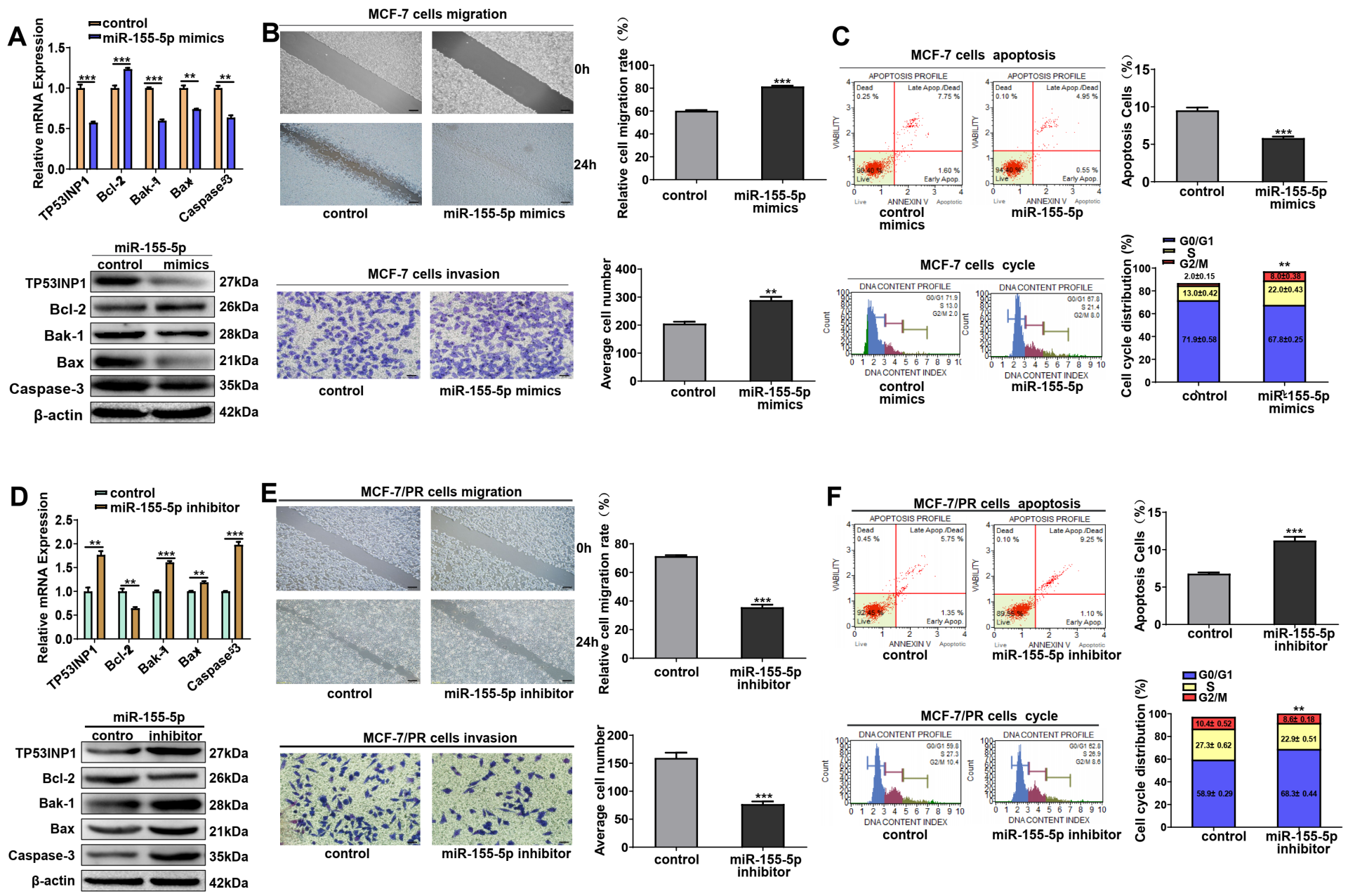

\section{Figure 3}

Ectopic expression miR-155-5p modulates breast cancer cell apoptosis, migration, and invasion. a Analysis of mRNA and protein levels of the target gene TP53INP1 and apoptosis-related genes Bcl-2, Bak1, Bax and Caspase-3 transfected with miR-155-5p mimics in MCF-7 cells. b Analysis of cells invasion and migration ability. $c$ Analysis of cells cycle distribution. $d$ Analysis of mRNA and protein levels of the target gene TP53INP1 and apoptosis-related genes transfected with miR-155-5p inhibitor in MCF-7/PR cells. e Analysis of cells invasion and migration ability. $f$ Analysis of cells cycle distribution. (The asterisks show difference significant as $* \star * P<0.001 ; * * P<0.01$ ) 

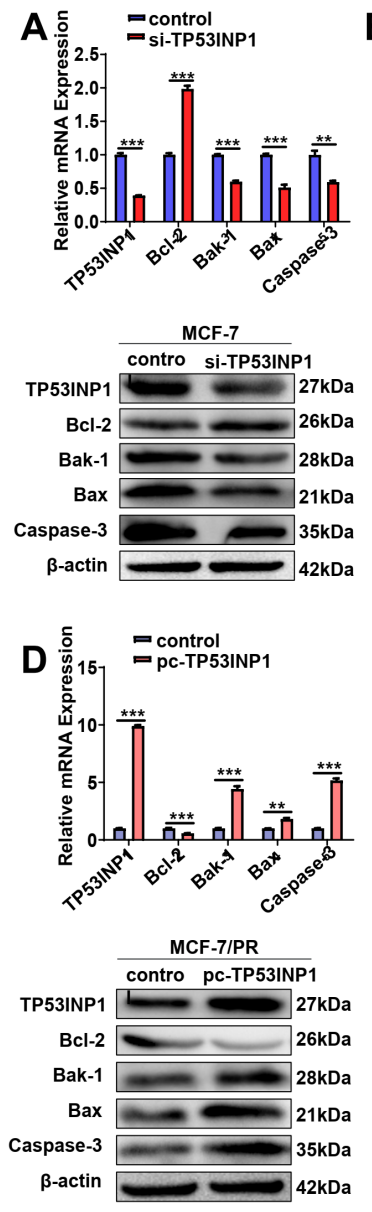

B
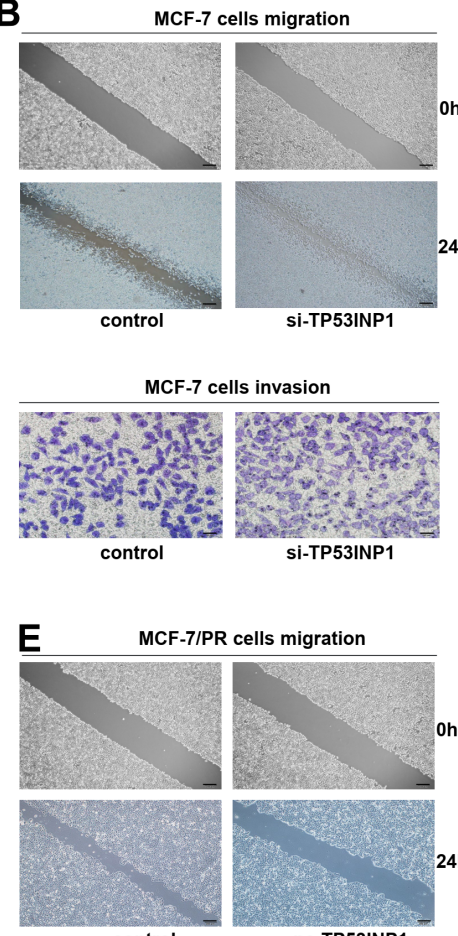

control
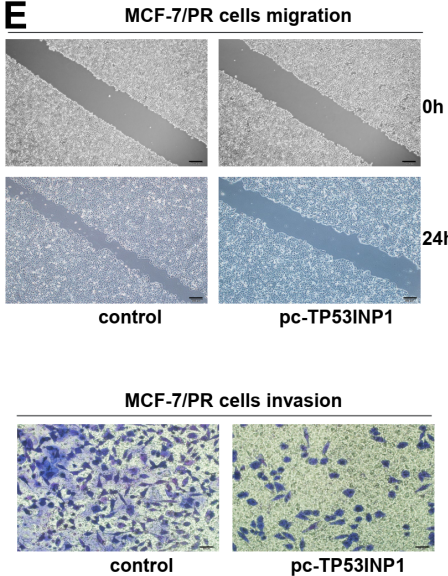

pc-TP53INP1
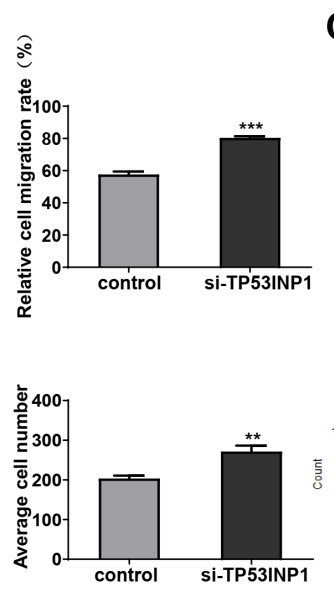
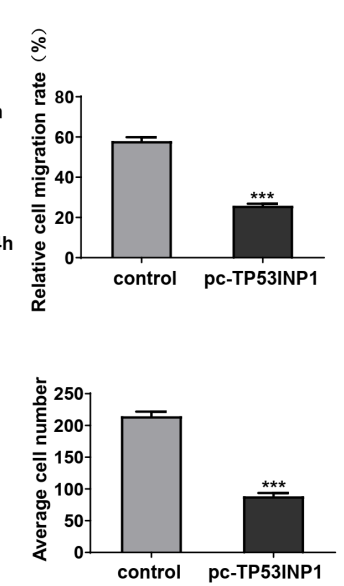

C
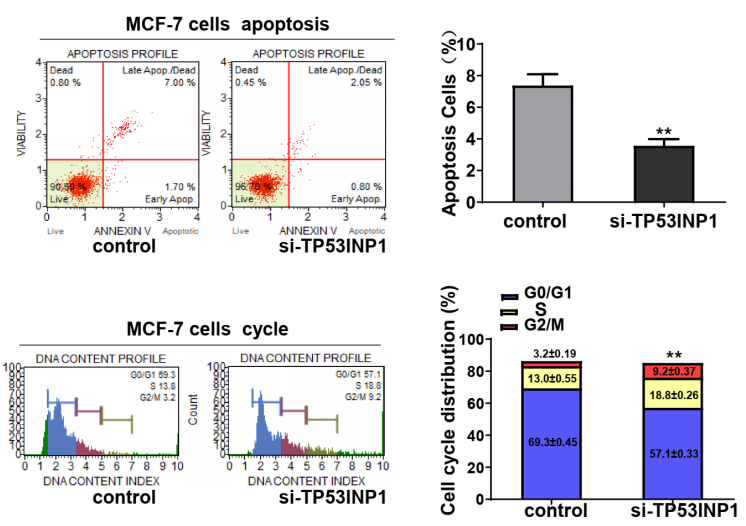

$\mathbf{F}$
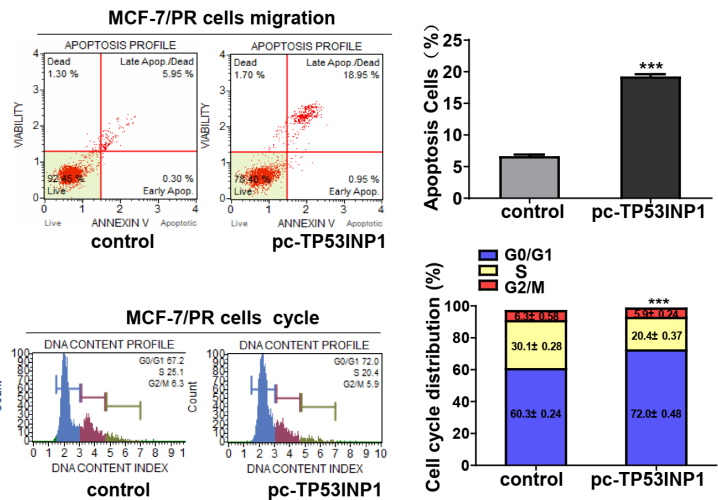

\section{Figure 4}

TP53INP1 expression affected breast cancer cell apoptosis, migration, and invasion. a Analysis of mRNA and protein levels of the target gene TP53INP1 and apoptosis-related genes transfected with TP53INP1 siRNAs in MCF-7 cells. b Analysis of cells invasion and migration ability. c Analysis of cells cycle distribution. d Analysis of mRNA and protein levels of the target gene TP53INP1 and apoptosis-related genes transfected with specific overexpression plasmids for TP53INP1 in MCF-7/PR cells. e Analysis of cells invasion and migration ability. $f$ Analysis of cells cycle distribution. (The asterisks show difference significant as $\left.{ }^{\star * *} \mathrm{P}<0.001 ; * \star \mathrm{P}<0.01\right)$ 
A 1) control

2) miR-155-5p inhibitor

3) Pc-TP53INP1

4) inhibitor+pc-TP53INP1

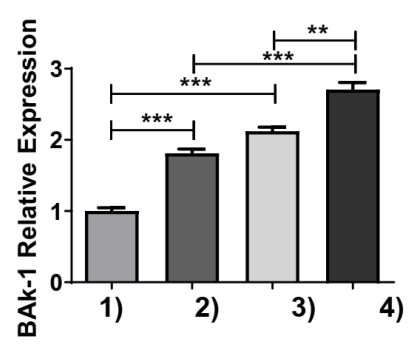

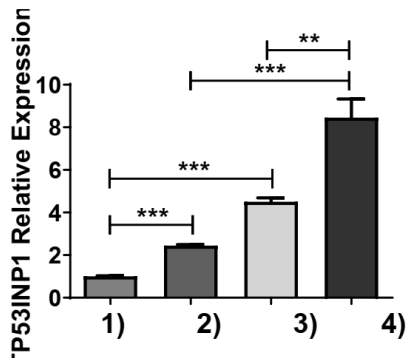

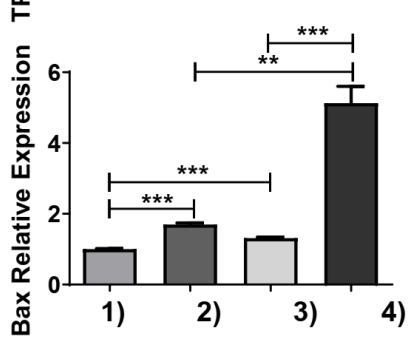

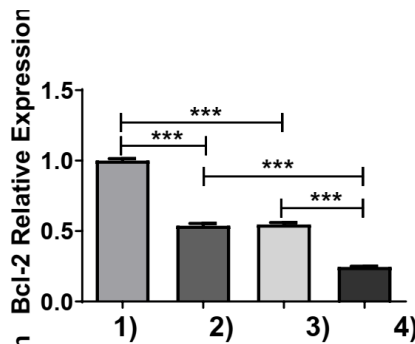

B $\begin{array}{ll}\text { 1) control } & \text { 2) miR-155-5p inhibitor } \\ \text { 3) pc-TP53INP14) inhibitor+pc-TP53INP1 }\end{array}$

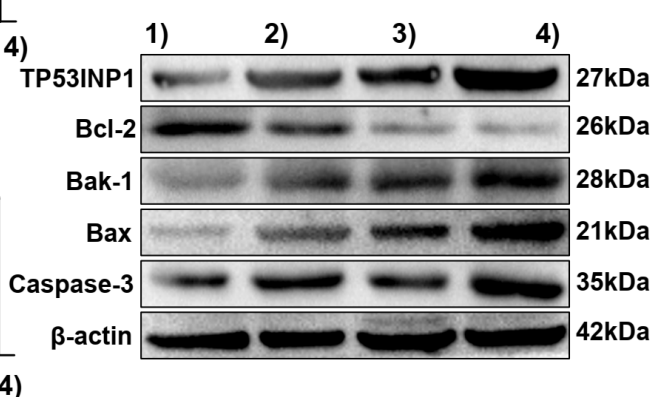

1)

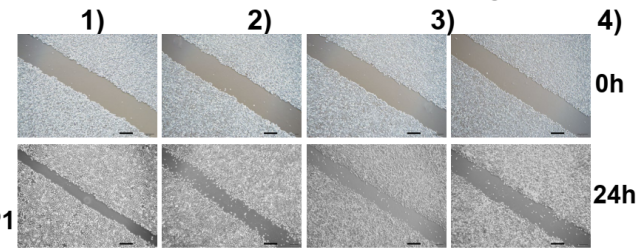

1)

2)

3)

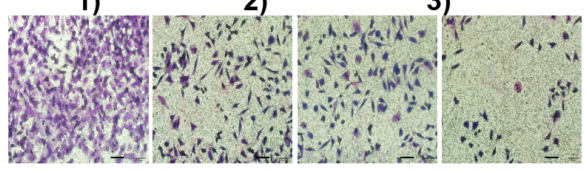

2)
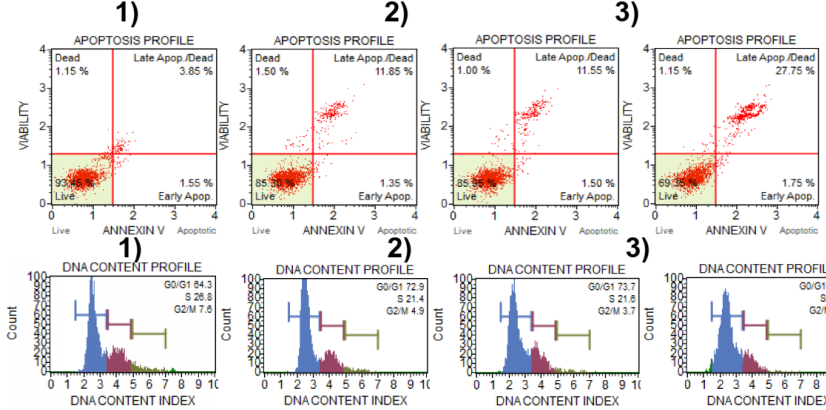

3)

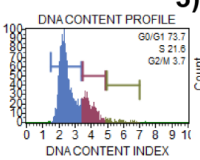

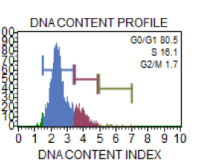

4)

4)

$\begin{array}{ll}D \text { 1) control 2) miR-155-5p inhibitor } & \text { 2) }\end{array}$

3) pc-TP53INP14) inhibitor+pc-TP53INP1

ฮั

4)
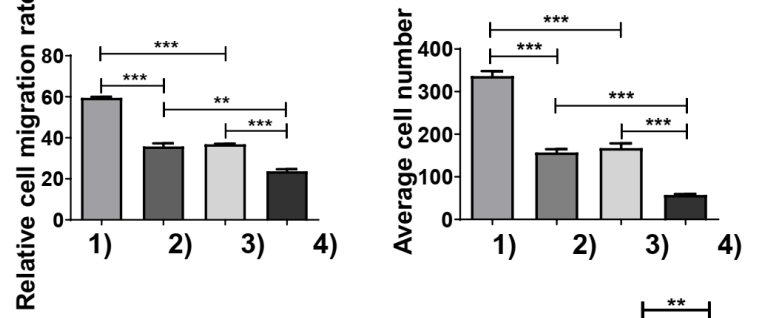

4)

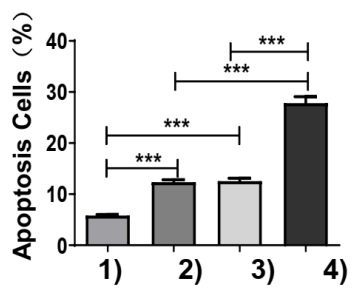

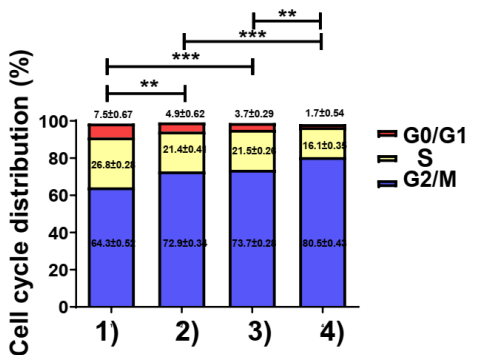

Figure 5

Synergistic effect of combination miR-155-5p-pcTP53INP1 on breast cancer cells apoptosis, migration and invasion. a qRT-qPCR analysis of TP53INP1 and apoptosis - related genes Bcl-2, Bak-1, Bax, Caspase3 mRNA level with the combination of miR-155-5p inhibitor and pc-TP53INP1. b Western blotting for TP53INP1, Bcl-2, Bak-1, Bax, Caspase-3 protein level. c Cells migration and invasion, apoptosis and cell cycle distribution analysis in MCF-7/PR with the combination of miR-155-5p inhibitor and pc-TP53INP1. d Quantify for wound healing assay, matrigel invasion, apoptosis, and cell cycle. (The asterisks show difference significant as ***P $<0.001$; ${ }^{*} \mathrm{P}<0.01$ ) 

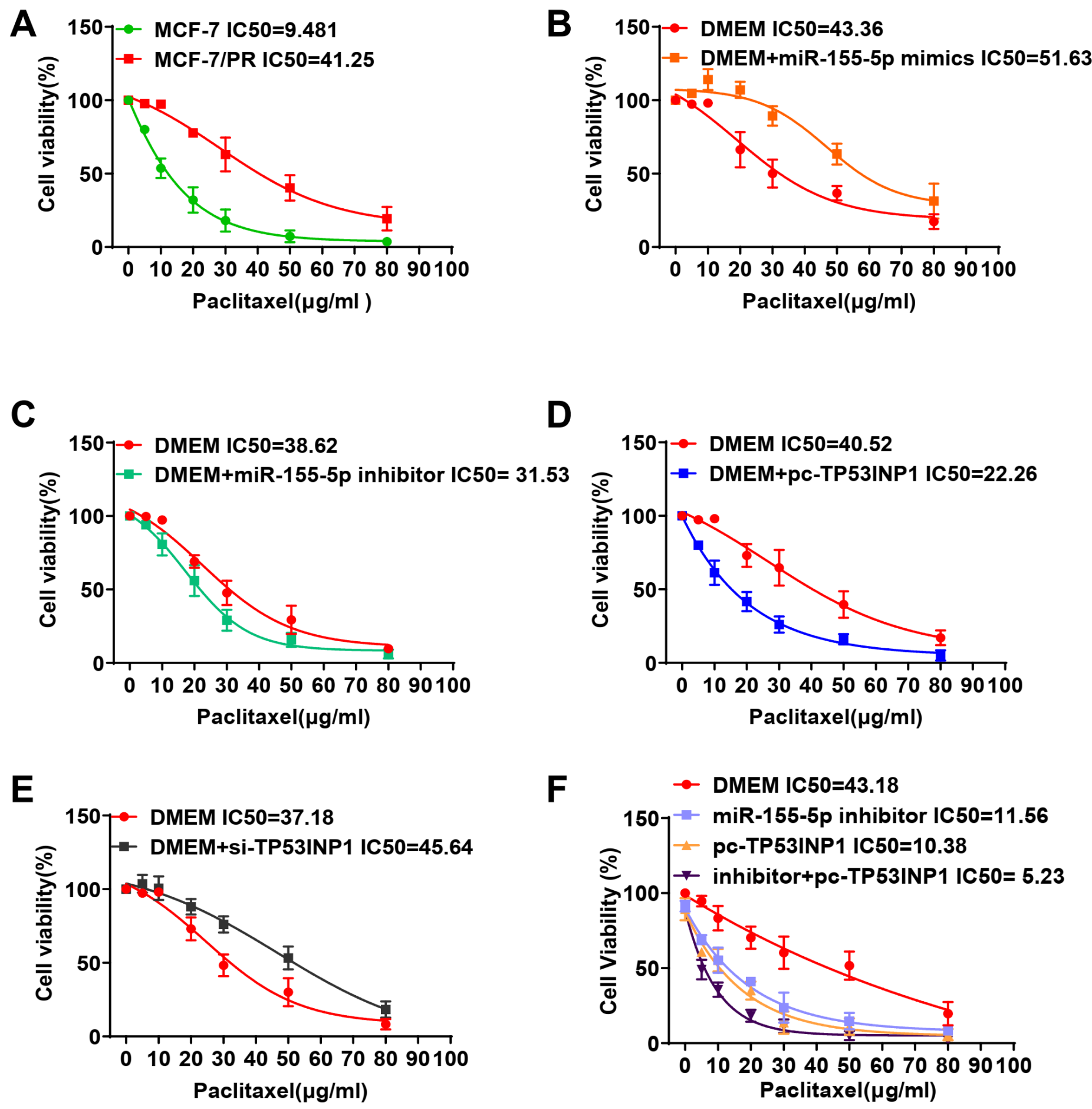

Figure 6

miR-155-5p promotes paclitaxel resistance by suppressing TP53INP1. a MCF-7 and paclitaxel-resistant cells MCF-7/PR were exposed to different concentrations of paclitaxel for $24 \mathrm{~h}$, and then cell viability was assayed after treatment with various concentrations of paclitaxel for $48 \mathrm{~h}$ by SRB assay. b-f paclitaxelresistant cells MCF-7/PR were co-transfected with miR-155-5p mimic/inhibitor or si-TP53INP1/ pcTP53INP1 for $24 \mathrm{~h}$, and then cell viability was assayed after treatment with various concentrations of paclitaxel for $48 \mathrm{~h}$ by SRB assay. Each experiment was repeated three times. 


\section{Supplementary Files}

This is a list of supplementary files associated with this preprint. Click to download.

- Figures1.tif 